Sharif University of Technology
Scientia Iranica
SCIENTIA
IRAN ICAA

\title{
Application of ultrasound wave for stimulation of asphaltene damaged reservoir rocks: An experimental study
}

\author{
B. Keshavarzi, M.H. Ghazanfari*, and C. Ghotbi \\ Department of Chemical and Petroleum Engineering, Sharif University of Technology, Tehran, Iran.
}

Received 30 November 2017; received in revised form 7 April 2018; accepted 26 June 2018

\section{KEYWORDS}

Ultrasound;

Stimulation;

Asphaltene

deposition;

Experimental.

\begin{abstract}
In this study, application of ultrasound wave for permeability enhancement of reservoir rocks was experimentally examined. In this regard, a specific core holder apparatus was designed with the ability of in-situ exposure of ultrasound to the plug in a high-pressure condition, which is a better representative of ultrasound application in real wellbores. The effect of ultrasound power and exposure time as well as probe-plug distance on permeability stimulation was evaluated. The results showed that ultrasound could stimulate the permeability of asphaltene-damaged rocks, in which its efficiency was significant in sandstone rock. Analysis of asphaltene content in the output fluid showed that, as a result of ultrasound exposure, $84 \%$ of deposited asphaltenes in the sandstone plug were removed, corresponding to $67 \%$ of permeability recovery. It was also found that the stimulated permeability increased with increasing exposure time and power, while it decreased with increasing probe-plug distance. However, an optimum value for exposure time and power, after which the permeability recovery was not significantly enhanced, was observed. Analysis of experiments also showed that probe-plug distance had the most prominent effect on recovery of damaged permeability in comparison to ultrasound time and power.
\end{abstract}

(C) 2018 Sharif University of Technology. All rights reserved.

\section{Introduction}

Until now, many different methods have been developed and applied for asphaltene deposition removal. These methods generally include mechanical treatment that uses different kinds of scrappers and pigging flow lines [1], thermal methods using hot oiling and steam treatment and chemical methods including mainly solvent, dispersant application and surfactant

\footnotetext{
*. Corresponding author. Tel.: +98-6616-5403,

Fax: (+98)-21-66622853;

E-mail addresses: behnam.keshavarzi67@gmail.com (B. Keshavarzi); ghazanfari@sharif.edu (M.H. Ghazanfari); ghotbi@sharif.edu (C. Ghotbi).
}

treatment [2]. Moreover, some new technologies, such as laser, bacteria, and production techniques, are also developed for asphaltene damage treatment $[1,3]$. Although the above-described methods are proved efficient in some cases, there are many disadvantages to them. For example, mechanical treatments are expensive and increase the risk of tool fishing and plugging of the perforation [4]. There are many environmental safety hazards concerning chemical methods [5], and formation could be damaged as a result of high temperature in thermal treatment [6]. Therefore, finding new technologies has always been a concern for dealing with asphaltene damage in petroleum industry. One of the methods, which has been of interest in the past decades, is the application of ultrasound wave.

Being a sound wave, ultrasound is transmitted 
through any substance, solid, liquid or gas, possessing elastic properties. The movement of the vibrating body (i.e., sound source) is transferred to the molecules of the medium, each of which transmits the motion to the adjoining molecules before returning to their original positions. For liquids and gasses, particle oscillation takes place in direction of the wave and causes longitudinal waves (compression and rarefaction cycles). During the compression cycle, the average distance between the molecules decreases, whilst this distance increases during rarefaction. If a sufficiently large negative pressure is applied to the liquid (during rarefaction period) such that the average distance between the molecules exceeds some critical distance, the liquid will break down and millions of microscopic bubbles (cavities) will be created [7]. These cavities expand under negative pressure and implode by positive pressure. Implosion of these cavities in liquid results in the great concentration of energy in the medium [8], which produces a powerful shearing action at the horn tip and causes the molecules to become intensely agitated [9]. The energy released by imploding cavities can be used for cleaning surfaces and separating foreign matters [10].

Many researchers have investigated the application of ultrasound wave technology in petroleum industry. These investigations include the use of ultrasound for improving the properties of oil, drilling fluid, etc., and some researchers have studied the use of ultrasound for enhanced oil recovery and fluid flow enhancement [11-17]. Duhon and Campbell [18] were the first group to investigate the effects of ultrasonic waves on fluid flow through porous media. They conducted a series of flood tests at the core-plug scale to characterize the behavior of the oil displacement by water with and without addition of sonic energy. The results of their work showed that the addition of sonic energy increased displacement efficiency. Cherskiy et al. [19] described a sharp increase in permeability of core samples saturated with fresh water in the presence of acoustic field. Beresnev and Johnson [20] provided a comprehensive review of methods using elastic wave stimulation of oil production, and mentioned that the application of elastic waves improved fluid percolation in porous media. Hamida and Babadagli [21] observed that ultrasound wave could enhance capillary imbibition oil recovery depending on the fluid, sound intensity, sound frequency, and the nature of matrix. In addition, Naderi and Babadagli $[22,23]$ revealed the positive effect of ultrasonic energy on heavy-oil recovery for rocks with different wettability conditions. In a field study, Abramov et al. [24] studied the use of ultrasound technology to enhance the recovery of oil from failing oil wells, and found that ultrasonic treatment could increase oil production by $50 \%$ for wells with permeability above $20 \mathrm{md}$ and the porosity greater than $15 \%$; however, for wells with lower permeability and porosity, ultrasound treatment is less successful. Many other works have also been published in this area including the impact of ultrasound on recovery of gravity drainage process [25], application of elastic waves for fluid flow enhancement through porous media [26], ultrasound assisted $\mathrm{CO}_{2}$ flooding [27], and some other works on ultrasound application for enhanced oil recovery purposes [28-32]. The cleaning act of ultrasound wave has also been under consideration by many researchers. Venkitaraman et al. [33] conducted a series of laboratory experiments to investigate the feasibility of using ultrasound energy to reduce formation damage caused by fines and mud solids. In their work, cores were damaged with drilling mud in a dynamic filtration cell; then, the damaged cores were treated with ultrasonic energy at various frequencies and intensities. The results of their work showed that permeability increased by a factor of three to seven after ultrasound treatment for cores that were damaged by mud solids and fines migration. Roberts et al. [34] investigated the role of ultrasound energy in reducing near-wellbore formation damage caused by organic deposits and polymers. They showed that mechanical agitation provided by acoustic waves re-suspended the paraffin and restored the effective permeability of the core to its undamaged condition. Wong et al. [35] examined the acoustic power needed to remove near-wellbore formation damage caused by fines and particles plugging pores as well as drilling-induced damage. The results of their work led to the design and construction of a slim, high-power, and high-frequency (above $10 \mathrm{kHz}$ ) downhole acoustic tool for field deployment. $\mathrm{Xu}$ et al. [36] examined ultrasound to remove oil from oil field sand samples, and showed that ultrasound assisted mechanical washing was an effective way to extract the oil from sands. A review of the cleaning applications of ultrasonic wave is available, done by Mason [37]. In this area, Shedid [6,38] was the first researcher to investigate the role of ultrasound wave in asphaltene damage removal in core plugs. In his work, the plug was damaged in the core holder by gradual injection of 60 pore volumes of asphaltenic oil; then, it was taken out of core holder and was exposed to ultrasound in a beaker in an ambient condition. He also took SEM images of the plug at different ultrasound exposure times, and observed that the application of the ultrasound irradiation not only removed the deposited asphaltene from the surface, but also created small micro-cavities at the plug. In addition, Shedid [6,38] found that the increase of ultrasonic time interval and/or frequency drastically improved damaged oil permeability. However, the condition of in-situ exposure was not provided in his work. 


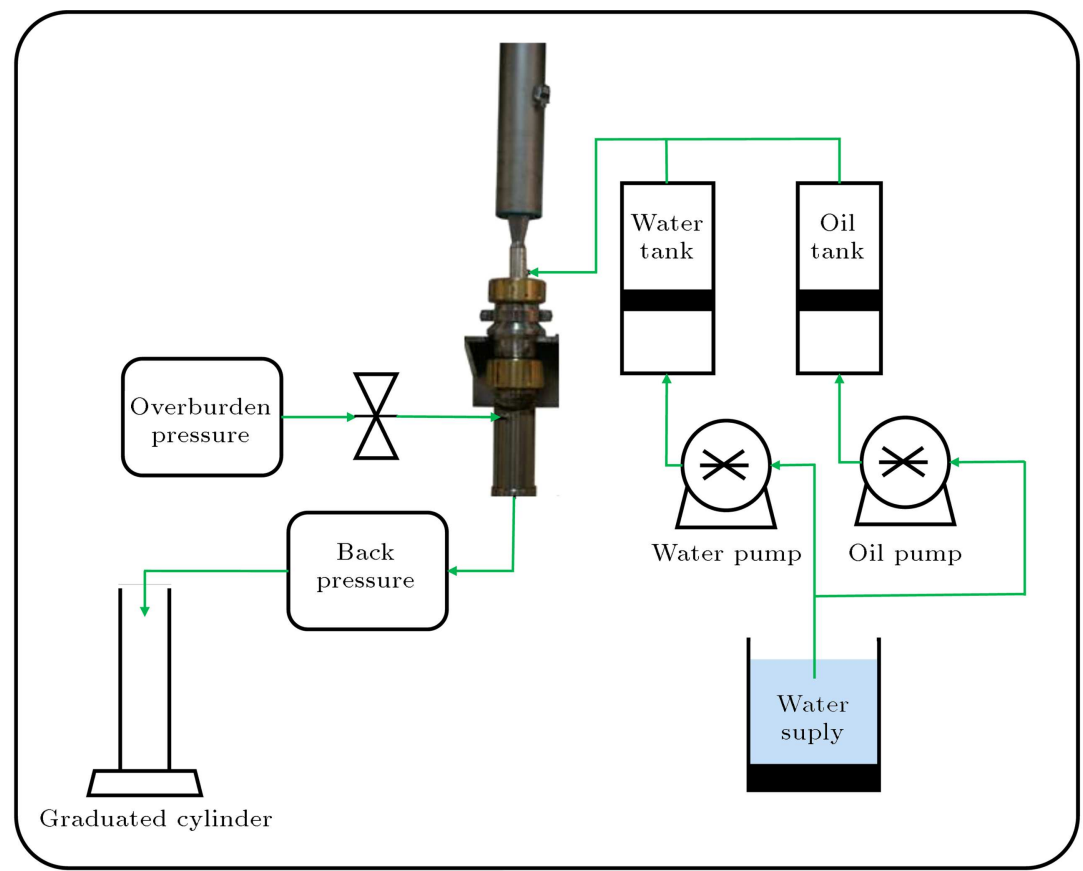

(a)

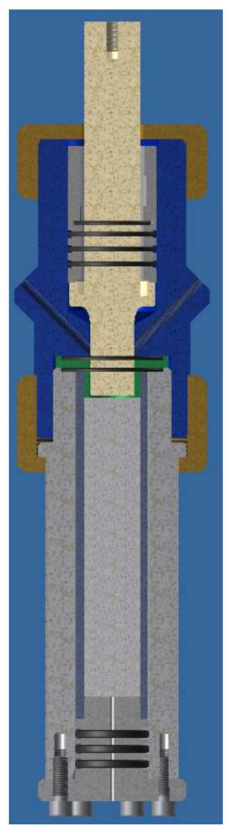

(b)

Figure 1. (a) Schematic of designed in-situ ultrasound exposure core flooding apparatus. (b) Section of the core holder.

This work may be introduced as an extension to the work reported by Shedid [6,38]. However, here, a specific core holder apparatus was designed with the ability of in-situ exposure of ultrasound directly to the plug in a high-pressure condition, which is a much better representative of ultrasonic application in real wellbores. The asphaltene deposition was induced in the core plug by flooding many pore volumes of asphaltenic oil, i.e., the same procedure as reported by Shedid [6,38]. The role of ultrasound exposure time, ultrasound power as well as ultrasound probeplug distance in stimulation efficiency was investigated. In addition, the efficiency of ultrasound on sandstone and carbonate rock types was compared. Moreover, the amounts of asphaltene deposited in the plug and asphaltene removed from the plug by ultrasound were evaluated by sampling output fluid from system and performing IP-143 tests.

\section{Experimental}

\subsection{Experimental set up}

In this work, a specific core holder apparatus was designed and utilized for the experiments. Specialty of this design is that ultrasound transducer is mounted on top of the core holder, and ultrasound probe with diameter of $3 \mathrm{~cm}$ and length of $25 \mathrm{~cm}$ is embedded in the core holder. This allows us to apply ultrasound wave directly to the plug within the holder in a highpressure condition. There is also an option to move the probe back and forth through the core holder to change the probe-plug distance. This distance could change from $0.6 \mathrm{~cm}$ to $4 \mathrm{~cm}$. The ultrasound exposure was applied using an ultrasound wave generator with the power up to 1000 watts and the frequency of $20 \mathrm{kHz}$. Figure 1(a) shows the experimental setup, while Figure 1(b) depicts the core holder and ultrasound probe. Two high-pressure transfer vessels were used for oil and brine, and two pairs of positive displacement pumps (one pair for oil injection and one for brine injection) were utilized to perform the injection jobs. The overburden pressure around the rubber sleeve was supported using a hand pump operating with water. Both injection and overburden pumps were connected to the water supply. The output fluid at the producing end of the core holder was collected using a graduated cylinder, and the producing pressure was controlled using a backpressure system supported by a nitrogen cylinder.

The experiments were performed on two different core plugs: one sandstone with absolute permeability of 115 md and porosity of $15.6 \%$ and a carbonate sample with permeability of $140 \mathrm{md}$ and $11.1 \%$ porosity. High permeability samples were selected to eliminate the permeability reduction due to pore plugging, causing severe damage to plug. Crude oil sample with API gravity of 21 and $8.91 \%$ asphaltene contents was used in the experiments.

\subsection{Experimental procedure}

\subsubsection{Flooding experiments}

After plug washing and desiccating, the core plug was placed in the core holder and the setup was assembled. Then, overburden pressure was provided 
using the hand pump. The core holder was connected to vacuum pump and was vacuumed for 6 hours. When the desired evacuation was achieved, the system was fully saturated with brine. Afterwards, brine injection began at a rate of $1 \mathrm{cc} / \mathrm{min}$ and continued for at least three pore volumes until a steady-state condition was well established, and complete water saturation in the plug was ensured.

In the next step, oil injection was initiated at a rate of $0.5 \mathrm{cc} / \mathrm{min}$ to push the water out of the plug and continued until the irreducible water saturation was reached. The original permeability of the plug to oil was recorded at this point, and oil injection continued with the same rate in order to create the damage. During the oil injection, asphaltene was deposited gradually and the permeability of the plug was reduced. In each experiment, oil injection continued to $40-45$ pore volumes of the plug, and the damaged permeability was recorded versus pore volumes of oil injected. After 40-45 pore volumes of oil injection, when no more permeability reduction was observed, oil injection stopped and ultrasound irradiation was performed to treat the damage. Then, the system was cooled for 20 minutes, and the oil injection was reinitiated. Since physical properties of the sonicated oil existing in the core holder may have changed under ultrasound exposure, the injection continued until the sonicated oils in the medium would leave the plug, original oil entered the system, and then the stimulated permeability was measured. The experiment was repeated at three ultrasound exposure times (10, 20, and 30 minutes), three ultrasound powers (100, 200, and 300 watts), and three different distances between ultrasound probe and plug $(0.6,1.6$, and $3.6 \mathrm{~cm})$ on the sandstone plug. Some experiments were also performed on a carbonate plug to evaluate the influence of ultrasound wave for asphaltene damage removal in a different rock type. It should be mentioned that the errors resulting from calculation of the permeabilities are $\pm 2 \mathrm{md}$.

\section{Results and discussion}

\subsection{Effects of ultrasound power and exposure time}

Table 1 presents the details of experiments. The power rates of ultrasound tool for Experiments 1-3, 4-6, and $7-9$, performed on sandstone plug, were 100, 200, and 300 watts, respectively while the distance between horn and plug was $0.6 \mathrm{~cm}$. The value of sandstone plug original permeability was calculated as $115 \mathrm{md}$. As stated previously, high permeability core plugs were used in this study to minimize the impact of pore plugging. Two mechanisms of pore plugging and surface deposition are responsible for permeability reduction in the asphaltene deposition process. Pore plugging

Table 1. Details of experiments.

\begin{tabular}{ccccccc}
\hline $\begin{array}{c}\text { Exp. } \\
\text { no. }\end{array}$ & Rock type & $\begin{array}{c}\text { Distance } \\
(\mathbf{c m})\end{array}$ & $\begin{array}{c}\text { Power } \\
\text { (watts) }\end{array}$ & $\begin{array}{c}\text { Ultrasound } \\
\text { exposure time } \\
(\mathbf{m i n})\end{array}$ & $\begin{array}{c}\text { Damaged } \\
\text { permeability } \\
(\mathbf{m d})\end{array}$ & $\begin{array}{c}\text { Stimulated } \\
\text { permeability } \\
\text { (md) }\end{array}$ \\
\hline 1 & Sandstone & 0.6 & 100 & 10 & 79.0 & 92.6 \\
2 & Sandstone & 0.6 & 100 & 20 & 73.5 & 102.6 \\
3 & Sandstone & 0.6 & 100 & 30 & 67.4 & 102.6 \\
4 & Sandstone & 0.6 & 200 & 10 & 77.4 & 99.4 \\
5 & Sandstone & 0.6 & 200 & 20 & 73.5 & 109.2 \\
6 & Sandstone & 0.6 & 200 & 30 & 70.5 & 111.1 \\
7 & Sandstone & 0.6 & 300 & 10 & 73.8 & 98.9 \\
8 & Sandstone & 0.6 & 300 & 20 & 69.4 & 110.4 \\
9 & Sandstone & 0.6 & 300 & 30 & 66.7 & 111.1 \\
10 & Sandstone & 1.6 & 300 & 10 & 57.8 & 78.4 \\
11 & Sandstone & 1.6 & 300 & 20 & 52.9 & 83.2 \\
12 & Sandstone & 1.6 & 300 & 30 & 50.1 & 84.3 \\
13 & Sandstone & 3.6 & 300 & 10 & 54.0 & 73.8 \\
14 & Sandstone & 3.6 & 300 & 20 & 45.3 & 75.2 \\
15 & Sandstone & 3.6 & 300 & 30 & 39.8 & 74.6 \\
16 & Carbonate & 0.6 & 200 & 10 & 94.0 & 101.5 \\
17 & Carbonate & 0.6 & 200 & 20 & 93.6 & 104.9 \\
18 & Carbonate & 0.6 & 200 & 30 & 92.6 & 105.5 \\
19 & Sandstone & 0.6 & 300 & 10 & 70.3 & 100.3 \\
\hline
\end{tabular}




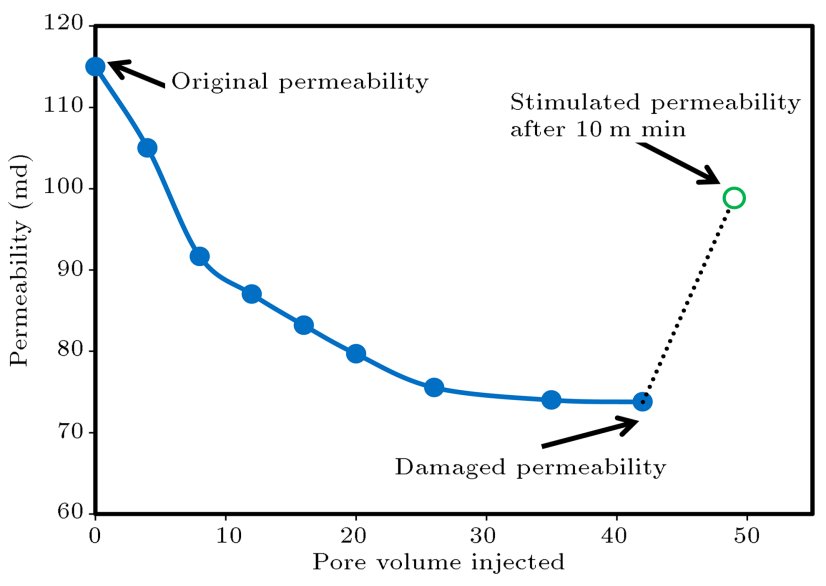

Figure 2. Process of permeability reduction due to asphaltene deposition during oil injection as well as permeability stimulation by ultrasonic exposure in sandstone rock according to Experiment 7 in Table 1.

happens when asphaltene particles/aggregates block some pore throats, which happens for small pores in low-permeability samples; however, surface deposition is a result of depositing asphaltene on the surface of pore throats and of diminishing the available flowing area. Pore plugging causes a severe permeability reduction due to little asphaltene deposition, while the extent of permeability reduction due to surface deposition is low [39]. Figure 2 shows a sample of oil injection process and the permeability reduction followed by the ultrasound exposure. As shown in Figure 2, permeability decreases during oil flooding because of asphaltene deposition until 40-45 pore volumes of oil injection finally reach a constant value. This constant permeability value can be justified as a result of establishing an equilibrium between surface deposition and entrainment, as reported by Wang and Civan [39]. Afterwards, oil injection stopped and the damaged plug was subjected to ultrasound exposure. The permeability increment due to sonication is observed as a dashed line.

The results of 19 performed experiments are presented in Table 1. According to the results, most of the damaged permeability has been recovered for most of the cases; at best, plug permeability has returned to $97 \%$ of the original permeability.

The extent of permeability stimulation in different cases is estimated by the parameter of permeability recovery, which is defined below:

$$
\mathrm{PR}=\frac{(\text { Stimulated Permeability-Damaged Permeability })}{(\text { Absolute Permeability-Damaged Permeability })} * 100 \text {. }
$$

To evaluate the influence of ultrasound exposure time and ultrasound power, values of permeability recovery are plotted against ultrasound exposure time for different values of power in Figure 3. As is shown

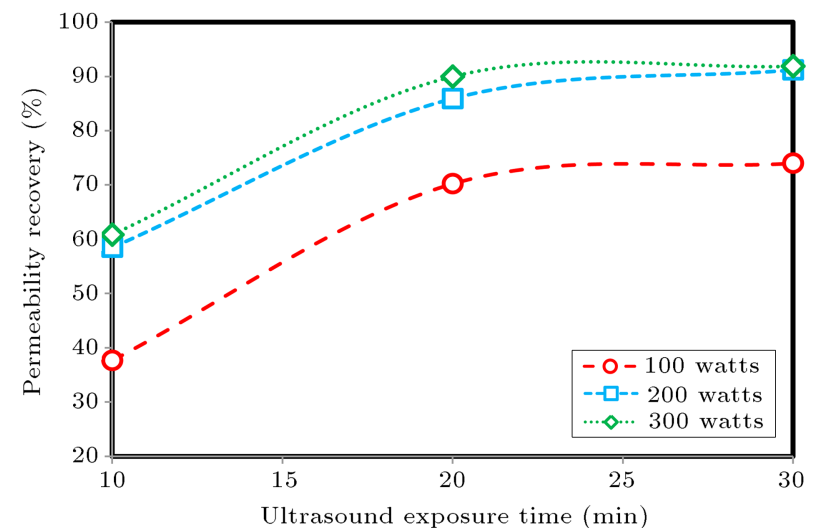

Figure 3. Permeability recovery versus ultrasound exposure time at different power levels.

in this figure, permeability recovery increases with ultrasound exposure time; however, the amount of increment between 10 and 20 minutes of sonication is much more than that of increment between 20 and 30 minutes. In addition, permeability recovery increment from 100 watts to 200 watts is much more than that from 200 watts to 300 watts. Therefore, it can be concluded that there is an optimum value for ultrasound exposure time and power after which no much enhancement in permeability is observed. The working mechanism of ultrasound is to import energy to the bulk of fluid and medium. This energy not only scrubs away deposited asphaltenes, but also breaks asphaltene particles/aggregates into very small parts and dissolves them in the fluid in the highly agitated condition present at the medium. Moreover, temperature increases by the act of ultrasound, which helps the process of dissolving asphaltene particles in the bulk fluid [40]. In order to investigate the impact of distance between wave source and the porous medium on the efficiency of ultrasound wave for asphaltene damage removal, Experiments 10-15 were designed (Table 1). The distance between ultrasound probe and plug was set to $1.6 \mathrm{~cm}$ for Experiments 10-12 and $3.6 \mathrm{~cm}$ for Experiments 13-15, while the ultrasound power was 300 watts; the results were compared to those of Experiments 7-9, in which the distance was $0.6 \mathrm{~cm}$. According to Biot [41], high-frequency sounds attenuate with distance from wave source, and the magnitude of attenuation is proportional to the square of the frequency. According to Hamida and Babadagli [42], when using Biot's theory, attenuation length of ultrasound at $20 \mathrm{kHz}$ ranges from 2 to 10 centimeters. Accordingly, since the probe-plug distance in our experiments is in the attenuation range, we should observe the effect of wave attenuation in our experiments. Figure 4 shows the variations in permeability recovery versus ultrasound exposure time for different ultrasound probe-plug distances. As is expected, the value of the permeability recovery 


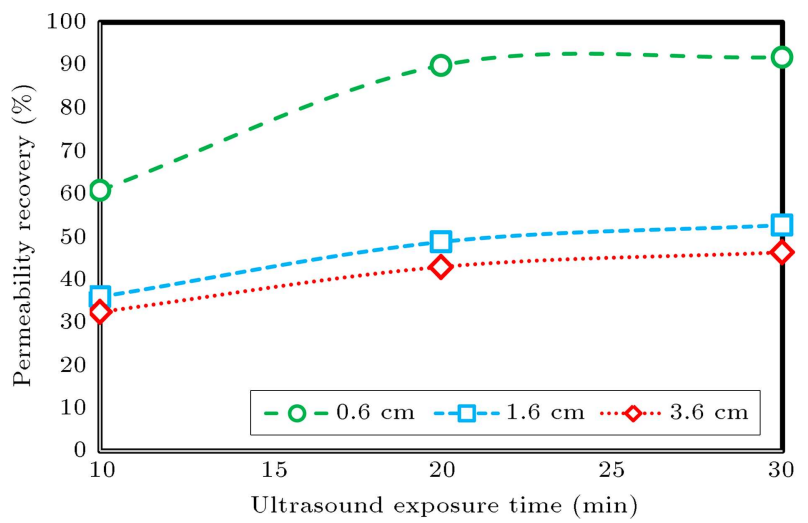

Figure 4. Permeability recovery versus ultrasound exposure time for different ultrasound probe-plug distances.

becomes lower for higher distances. This demonstrates the impact of attenuation on stimulation efficiency. It should be kept in mind that even though penetration length of ultrasound in the porous medium is not great, the problem of asphaltene deposition occurs mainly at short distances, i.e., near-wellbore region. Fluid pressure decreases in the near-wellbore region because of fluid drawdown, which increases the risk of asphaltene precipitation. In addition, in comparison to further distances in reservoir, the ratio of flow/porevolume is much greater in the near-wellbore region. Thus, much of the permeability reduction occurs in small distances due to asphaltene deposition, which is reachable by ultrasound.

\subsubsection{Comparison of influencing factors}

Time, power, and distance are the three ultrasoundrelated parameters. The extent of influence of each parameter in permeability recovery as well as the interaction of these parameters needs to be studied for further implementation. Figure 5 depicts the plot of the main effects for each of these three parameters. According to this figure, probe-plug distance has the most prominent effect on the amount of permeability recovery. Obviously, this could be due to wave attenuation at greater distances. In addition, according to Figure 6, great interaction between distance and both time and power is observed, such that, at greater probe-plug distances, the influence of time and power on permeability recovery weakens. The interaction of parameters of power and time also can be observed in Figure 6.

\subsubsection{Performance of the ultrasound exposure in carbonate rock}

A large portion of reservoirs around the world is carbonate, which may suffer from asphaltene deposition damages. The application of ultrasound wave in a carbonate sample was investigated through Experiments 16-18, as given in Table 1. During oil injection processes, considerable reductions in the permeability of sample were observed. The values of damaged and stimulated permeabilities are reported in Table 1. Figure 7 also compares the results of sonication in the carbonate plug with the sandstone with the same experiment parameters. It appears that the application of ultrasound wave for permeability recovery has not been efficient in carbonate samples. The amount of permeability recovery has been $27.3 \%$ at best, showing lower stimulated permeability ratio in comparison to those obtained in Experiments 1-15 for sandstone sample. This observation may be rationalized by the

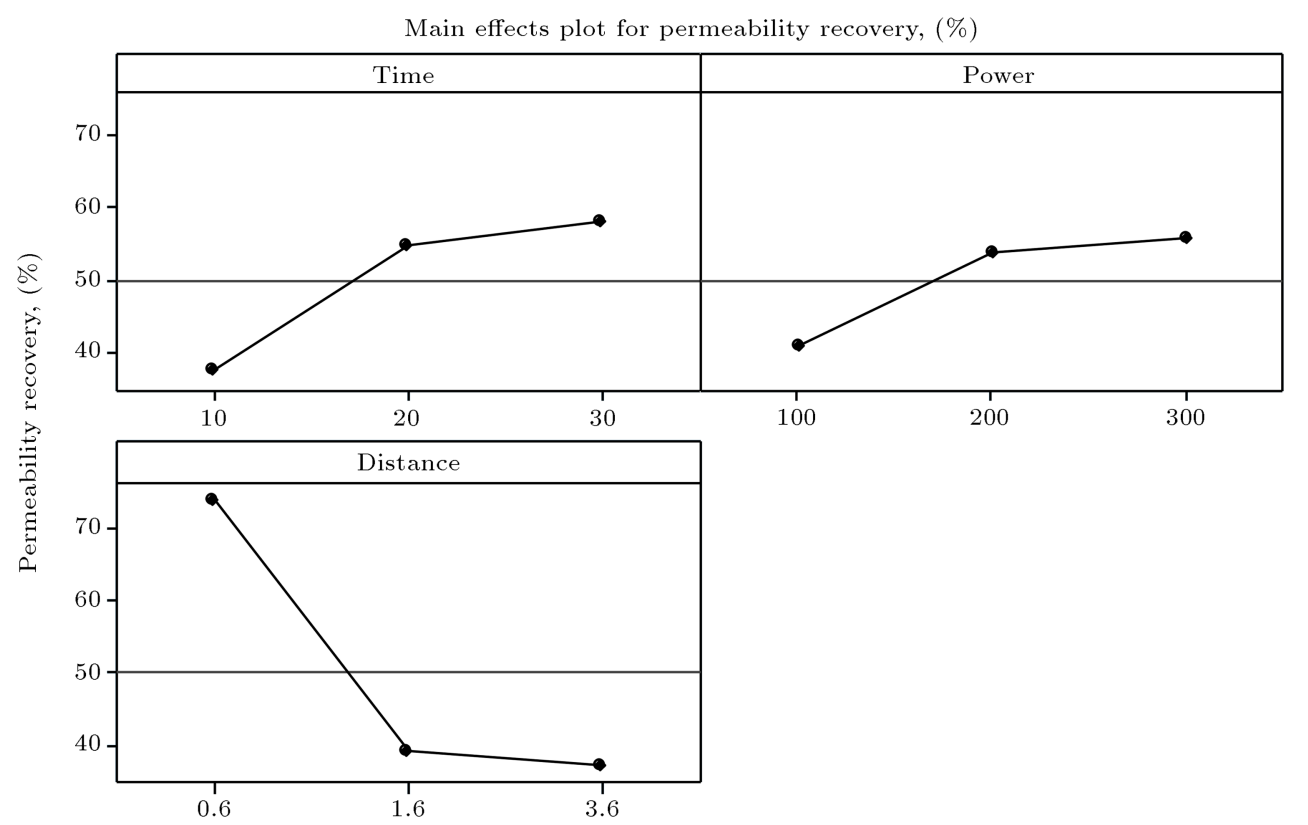

Figure 5. Main effect plot of permeability recovery for ultrasound parameters of time, power and distance. 
Interaction plot for permeability recovery (\%)

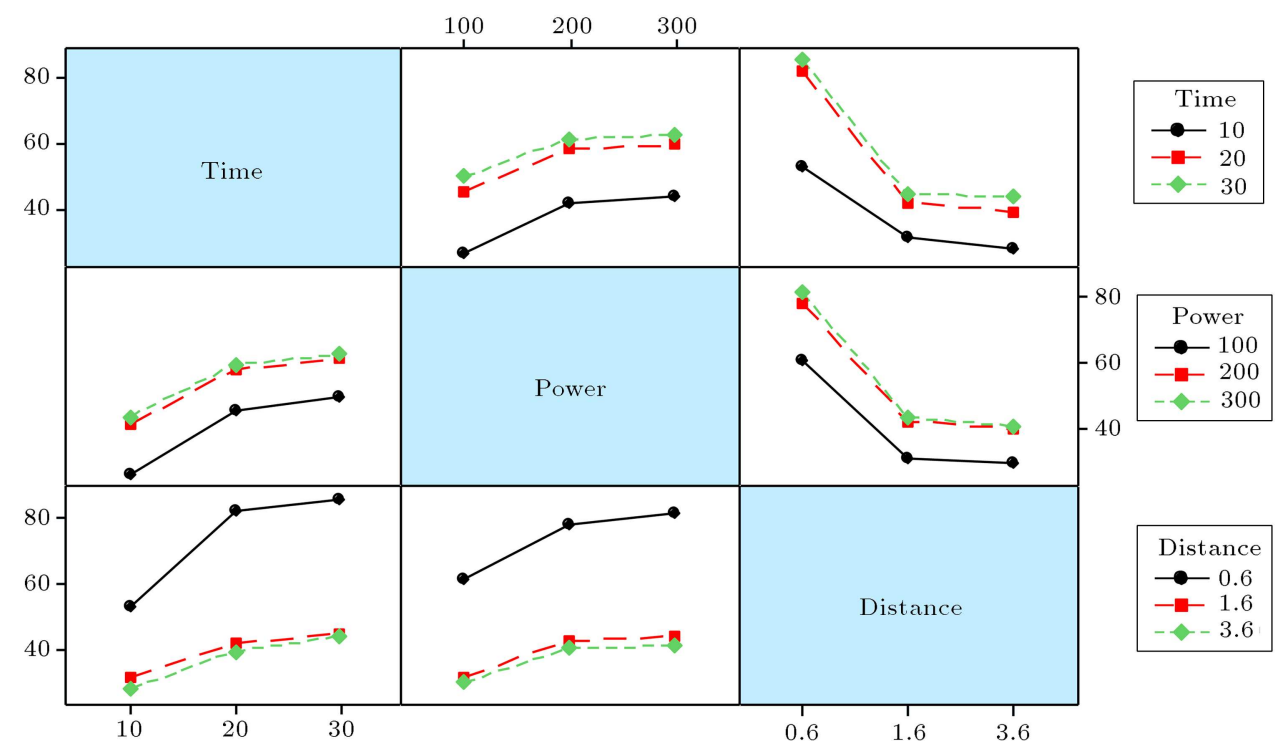

Figure 6. Plot of interactions between pairs of ultrasound parameters of time, power, and distance.

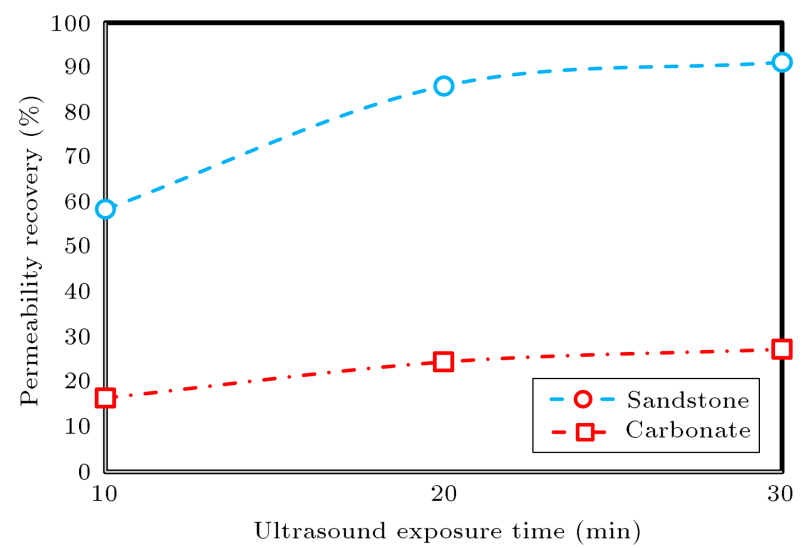

Figure 7. Permeability recovery versus ultrasound exposure time for sandstone and carbonate rock samples.

strongly oil wettability of the carbonate sample, which tends to keep the asphaltene particles stuck to the pore surface.

\subsubsection{Evaluation of the asphaltene deposition and asphaltene damage removal}

According to the previous sections, the permeability decreases during oil injection because of asphaltene deposition. Afterwards, by ultrasound exposure, deposited asphaltenes are removed from the plug, hence the permeability enhances. To support this argument, the asphaltene deposition during gradual oil injection as well as asphaltene removal from plug by sonication was calculated during one of the experiments. For this purpose, Experiment 19 was conducted. In this experiment, 30 pore volumes of oil sample were injected gradually into the sandstone plug, and 6 samples of the exiting oil were assumed during oil injection for IP-143 tests. After 30 pore volumes of oil injection,

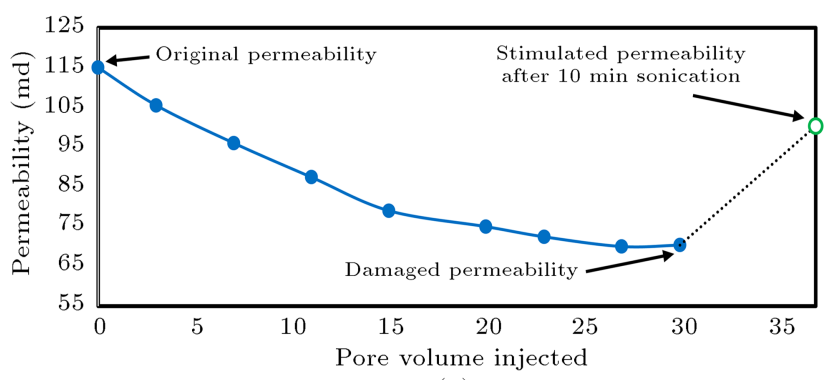

(a)

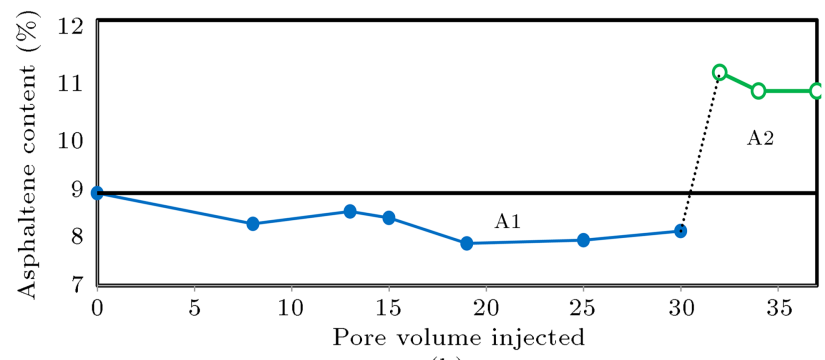

(b)

Figure 8. (a) Process of permeability reduction due to asphaltene deposition during oil injection as well as permeability stimulation by ultrasonic exposure. (b) Asphaltene content of output oil of plug before and after ultrasound exposure.

sonication was carried out for 10 minutes with the power of 300 watts, while the probe of ultrasound was at a distance of $0.6 \mathrm{~cm}$ from plug. Three other samples of the exiting oil were also taken after sonication for IP-143 tests to evaluate efficiency of asphaltene removal. Figure 8(a) shows the variations in the plug permeability versus pore volume of oil injection, while Figure 8(b) shows the variations of asphaltene content of exiting oil from plug. The gradual permeability reduction shown in Figure $8(\mathrm{a})$ is in agreement with 
the increment in the asphaltene deposition shown in Figure 8(b) until reaching 30 pore volumes of oil injection. An enhancement in the permeability after ultrasound exposure is observed in Figure 8(a), which could be explained with respect to asphaltene removal act of ultrasound wave, as shown in Figure 8(b), by an increment in the asphaltene content of the output oil.

The straight line in Figure 8(b) shows the asphaltene content of original oil, which is equal to $8.91 \%$. The difference between asphaltene content of original oil and asphaltene content at each point gives percentage of asphaltene deposition or the asphaltene removal. Therefore, the area below the line of original asphaltene content (A1) gives deposited asphaltene value in the medium, and the area above the line (A2) gives removed asphaltene from plug by sonication. Considering the mass of the 30 pore volumes of injected oil and area A1, the value of the deposited asphaltene is 0.88 gr. Moreover, considering seven pore volumes of the oil existing in the core holder during ultrasound application, which dissolves/carries and removes the asphaltene from the plug as calculated by area A2, the value of asphaltene removed from plug is $0.71 \mathrm{gr}$. This states that $84 \%$ of the deposited asphaltenes has been removed from the medium by ultrasound. Besides, according to Figure 8(a), the stimulated permeability, which has returned to $100.3 \mathrm{md}$ and is equivalent to $67 \%$ of permeability recovery, corresponds to $84 \%$ asphaltene removal from the plug.

\section{Conclusions}

In this work, a specific core holder apparatus was successfully designed and utilized for investigating the impact of in-situ exposure of ultrasound for stimulating asphaltene damaged reservoir rocks. The experiments were performed under different conditions of ultrasound power and exposure time as well as the ultrasound probe-plug distances. Two rock samples of sandstone and carbonate were used in the experiments. The major conclusions drawn from results of this work can be summarized as follows:

- Ultrasound could stimulate the damaged permeability induced by asphaltene deposition. However, its efficiency in sandstone rocks is much greater than that in carbonate rocks;

- The amount of permeability recovery increased with increasing ultrasound exposure time and power and decreased with increasing the ultrasound probe-plug distance; however, an optimum value for ultrasound exposure time and ultrasound power was observed after which the value of stimulated permeability was not improved significantly;

- Analysis of asphaltene content in the output fluid showed that, as a result of ultrasound exposure, $84 \%$ of deposited asphaltenes in the sandstone plug was removed, corresponding to $67 \%$ permeability recovery;

- Analysis of experiments showed that probe-plug distance had the most prominent effect on recovery of damaged permeability in comparison to time and power of ultrasound;

- The results obtained in this work facilitate a better understanding of the role of ultrasound in stimulation of asphaltene-induced formation damage;

- The designed setup may be applicable to the analysis of ultrasound stimulation of damaged induced by drilling fluids, inorganic scales and wax deposition in the wellbors.

\section{References}

1. Leontaritis, K.J. and Mansoori, G.A. "Asphaltene deposition: a survey of field experiences and research approaches", J. Pet. Sci. Eng., 1(3), pp. 229-239 (1988).

2. Bernadiner, M. "Advanced asphaltene and paraffin control technology", SPE International Symposium on Oilfield Chemistry, Society of Petroleum Engineers (1993).

3. Zekri, A.Y., Shedid S.A., and Alkashef, H. "A new technique for treatment of permeability damage due to asphaltene deposition using laser technology". J. Pet. Sci. Eng., 59(3), pp. 300-308 (2007).

4. Straub, T., Autry, S., and King, G. "An investigation into practical removal of downhole paraffin by thermal methods and chemical solvents", SPE Production Operations Symposium, Society of Petroleum Engineers (1989).

5. Samuelson, M. "Alternatives to aromatics for solvency of organic deposits", SPE Formation Damage Control Symposium, Society of Petroleum Engineers (1992).

6. Shedid, S.A. "An ultrasonic irradiation technique for treatment of asphaltene deposition", J. Pet. Sci. Eng., 42(1), pp. 57-70 (2004).

7. Mason, T.J. and Phillip, J. "Applied sonochemistry", Wiley-VCH Weinheim, Germany (2002).

8. Suslick, K.S., Didenko, Y., Fang, M.M., Hyeon, T., Kolbeck, K.J., McNamara, W.B., Mdleleni, M.M. and Wong, M. "Acoustic cavitation and its chemical consequences", Phil. Trans. R. Soc. Lond. A, 357(1751), pp. 335-353 (1999).

9. Gollapudi, U., Bang, S., and Islam, M. "Ultrasonic treatment for removal of asphaltene deposits during petroleum production", SPE Formation Damage Control Symposium, Society of Petroleum Engineers (1994).

10. Gizem Gunal, O. and Islam, M. "Alteration of asphaltic crude rheology with electromagnetic and ultrasonic irradiation", J. Pet. Sci. Eng., 26(1), pp. 263-272 (2000). 
11. Salehzadeh, M., Akherati, A., Ameli, F., and Dabir, B. "Experimental study of ultrasonic radiation on growth kinetic of asphaltene aggregation and deposition", Can. J. Chem. Eng., 94(11), pp. 2202-2209 (2016).

12. Shi, C., Yang, W., Chen, J., Sun, X., Chen, W., An, H., Duo, Y., and Pei, M. "Application and mechanism of ultrasonic static mixer in heavy oil viscosity reduction", Ultrason. Sonochem., 37, pp. 648-653 (2017).

13. Amani, M., Al-Juhani, S., Al-Jubouri, M., Yrac, R., and Taha, A. "Application of ultrasonic waves for degassing of drilling fluids and crude oils", Adv. in Pet. Exp. and Dev., 11(2), pp. 21-30 (2016).

14. Zou, C., Zhao, P., Ge, T., Li, D., Ye, H., and Huang, G. "Bitumen recovery from Buton oil sands using a surfactant under the effect of ultrasonic waves", Energy Sources, Part A, 38(2), pp. 270-276 (2016).

15. Zhao, X., Zhang, X., Liu, L., Fan, L., and Ge, D. "Effect of ultrasonic reactor and auxiliary stirring on oil removal from oily sludge", Environ. Technol., 38(24), pp. 3109-3114 (2017).

16. Korkut, I. and Bayramoglu, M. "Ultrasound assisted biodiesel production in presence of dolomite catalyst", Fuel, 180, pp. 624-629 (2016).

17. Nagai, M., Seiyama, H., and Kasagi, M. "Effects of ultrasonic irradiation on the viscosity of fuel oils", Fuel, 61(11), pp. 1160-1161 (1982).

18. Duhon, R. and Campbell, J. "The effect of ultrasonic energy on flow through porous media", 2nd Annual Eastern Regional Meeting of SPE/AIME, Charleston, WV (1965).

19. Cherskiy, N., Tsarev, V., Konovalov, V., and Kusnetsov, O. "The effect of ultrasound on permeability of rocks to water", Transactions (Doklady) of the USSR Academy of Sciences, Earth Science Section (1977).

20. Beresnev, I.A. and Johnson, P.A. "Elastic-wave stimulation of oil production; a review of methods and results", Geophysics, 59(6), pp. 1000-1017 (1994).

21. Hamida, T. and Babadagli, T. "Effect of ultrasonic waves on the capillary imbibition recovery of oil", SPE Asia Pacific Oil and Gas Conference and Exhibition, Society of Petroleum Engineers (2005).

22. Naderi, K. and Babadagli, T. "Effect of ultrasonic intensity and frequency on heavy-oil recovery from different wettability rocks", International Thermal Operations and Heavy Oil Symposium, Society of Petroleum Engineers (2008).

23. Naderi, K. and Babadagli, T. "Influence of intensity and frequency of ultrasonic waves on capillary interaction and oil recovery from different rock types", Ultrason. Sonochem., 17(3), pp. 500-508 (2010).

24. Abramov, V.O., Mullakaev, M.S., Abramova, A.V., Esipov, I.B., and Mason, T.J. "Ultrasonic technology for enhanced oil recovery from failing oil wells and the equipment for its implemention", Ultrason. Sonochem., 20(5), pp. 1289-1295 (2013).
25. Keshavarzi, B., Karimi, R., Najafi, I., Ghazanfari, M.H., and Ghotbi, C. "Investigating the role of ultrasonic wave on two-phase relative permeability in a free gravity drainage process", Sci. Iran., 21(3), p. 763 (2014).

26. Keshavarzi, B., Karimi, R., Najafi, I., Ghazanfari, M.H., Amani, M., and Ghotbi, C. "Investigation of low frequency elastic wave application for fluid flow percolation enhancement in fractured porous media", J. Pet. Sci. Tech., 31(11), pp. 1159-1167 (2013).

27. Hamidi, H., Haddad, A.S., Mohammadian, E., Rafati, R., Azdarpour, A., Ghahri, P., Ombewa, P., Neuert, T., and Zink, A. "Ultrasound-assisted $\mathrm{CO} 2$ flooding to improve oil recovery", Ultrason. Sonochem., 35, pp. 243-250 (2017).

28. Mohsin, M. and Meribout, M. "An extended model for ultrasonic-based enhanced oil recovery with experimental validation", Ultrason. Sonochem. 23, pp. 413423 (2015).

29. Abramov, V.O., Abramova, A.V., Bayazitov, V.M., Altunina, L.K, Gerasin, A.S., Pashin, D.M., and Mason, T.J. "Sonochemical approaches to enhanced oil recovery", Ultrason. Sonochem., 25, pp. 76-81 (2015).

30. Mullakaev, M.S., Abramov, V.O., and Abramova, A.V. "Development of ultrasonic equipment and technology for well stimulation and enhanced oil recovery", J. Pet. Sci. Eng., 125, pp. 201-208 (2015).

31. Wang, Z. and $\mathrm{Xu}, \mathrm{Y}$. "Review on application of the recent new high-power ultrasonic transducers in enhanced oil recovery field in China", Energy, 89, pp. 259-267 (2015).

32. He, S., Tan, X., Hu, X., and Gao, Y. "Effect of ultrasound on oil recovery from crude oil containing sludge", Environ. Technol., 7, pp. 1-7 (2018).

33. Venkitaraman, A., Roberts, P., and Sharma, M. "Ultrasonic removal of near wellbore damage caused by fines and mud solids", SPE 27388 in SPE Intl Symposium on Formation Damage Control, Lafayette, Louisiana (1994).

34. Roberts, P., Adinathan, V., and Sharma, M. "Ultrasonic removal of organic deposits and polymer-induced formation damage", SPE Dril. Comp., 15(1) pp. 19-24 (2000).

35. Wong, S.W., van der Bas, F., Zuiderwijk, P., Birchak, B., Han, W., Yoo, K., and van Batenburg, D. "Highpower/high-frequency acoustic stimulation: a novel and effective wellbore stimulation technology", SPE Prod. Facil., 19(04), pp. 183-188 (2004).

36. Xu, Y., Langbauer, C., and Hofstaetter, H. "The application of ultrasonic technology for cleaning oil contaminated sand", SPE Asia Pacific Health, Safety, Security, Environment and Social Responsibility Conference, Society of Petroleum Engineers (2017).

37. Mason, T.J. "Ultrasonic cleaning: An historical perspective", Ultrason. Sonochem., 29 pp. 519-523 (2016).

38. Shedid, S.A. "A novel technique of asphaltene depo- 
sition treatment using ultrasonic irradiation", J. Pet. Sci. Tech., 20(9-10), pp. 1097-1118 (2002).

39. Wang, S. and Civan, F. "Productivity decline of vertical and horizontal wells by asphaltene deposition in petroleum reservoirs", SPE International Symposium on Oilfield Chemistry, Society of Petroleum Engineers (2001).

40. Mousavi, S.M., Ramazani, A., Najafi, I., and Davachi, S.M. "Effect of ultrasonic irradiation on rheological properties of asphaltenic crude oils", Pet. Sci., 9(1), pp. 82-88 (2012).

41. Biot, M.A. "Theory of propagation of elastic waves in a fluid-saturated porous solid. II. Higher frequency range", J. Acoust. Soc. Am, 28(2), pp. 179-191 (1956).

42. Hamida, T. and Babadagli, T. "Displacement of oil by different interfacial tension fluids under ultrasonic waves", Col. Surf. A, 316(1), pp. 176-189 (2008).

\section{Biographies}

Behnam Keshavarzi obtained BS and MS degrees in Petroleum Engineering from Sharif University of Technology, Tehran, Iran. He is currently a $\mathrm{PhD}$ student at University of Tehran. He has authored/coauthored a number of publications in the area of ultrasonic applications in the oil industry, well testing and surface phenomena. His research interests include ultrasound stimulation, enhanced oil recovery, drilling fluids and dynamic surface phenomena.

Mohammad Hossein Ghazanfari obtained a BS degree from Isfahan University of Technology, Iran, and $\mathrm{PhD}$ and $\mathrm{MS}$ degrees in Chemical Engineering from Sharif University of Technology, Tehran, Iran. He is currently Associate Professor of Chemical and Petroleum Engineering and his research interests include modeling of transport in porous media, micro/core scale EOR studies, and asphaltene precipitation/deposition in static/dynamic conditions.

Cyrus Ghotbi was born in 1956 in Tehran, Iran. He obtained his BS degree from the Department of Chemical Engineering at Sharif University of Technology, Tehran, Iran, in 1978, and MS and PhD degrees in Petroleum Engineering from the French Institute of Petroleum (FIP), Paris, in 1981 and 1984, respectively. He is presently Professor of Chemical Engineering at Sharif University of Technology, Tehran, Iran. His research interests include thermodynamics, separation processes, and petroleum characterization. Professor Ghotbi is the author of more than 50 papers published in international journals, and about 90 papers presented at international and national conferences. 